\title{
Job Satisfaction towards Organizational Change during COVID - 19 Pandemic: A Study of Teaching Employees Working in +2 Private Schools of North Bihar
}

\author{
Dr. Chandan Kumar Sinha ${ }^{1 *}$, Prof. Anis Ahmad ${ }^{2}$
}

${ }^{1} \mathrm{Ph} . \mathrm{D}$ from University Department of Psychology, L. N. Mithila University, Darbhanga - 846004, India

${ }^{2}$ University Department of Psychology, L. N. Mithila University, Darbhanga - 846 004, India

DOI: $10.36347 /$ sjahss.2020.v08i10.002

| Received: 29.09.2020 | Accepted: 16.10.2020 | Published: 19.10.2020

*Corresponding author: Dr. Chandan Kumar Sinha

Abstract

Original Research Article

The present study was aimed at studying the Job Satisfaction towards organizational change during COVID - 19 among male and female teachers working in +2 private schools with particular reference to North Bihar, India. It is undoubtedly fact that in recent years our government, educator's organizations and other groups have sought to improve the public image of the teaching occupation so as to attract more people in to the occupation during COVID 19. Hence, the present piece of research work is of utmost value on the problem cited above. In the present investigation, total sample consisted of one hundred fifty $(\mathrm{N}=150)$ comprising male $(n=75)$ and female $(n=75)$ teachers working in +2 Private Schools were randomly selected from different private schools of North Bihar. The districts viz., Darbhanga, Madhubani and Samastipur were given priority for collecting the data. Data were collected through questionnaire schedules on the sample. Having obtained the data on the items of the schedules, individual scores were summed up and tabulated according to procedure of the scales for giving statistical treatment. Results revealed the fact that there is no significant difference between male and female teachers working in +2 private Schools of North Bihar in their degree of perceived reactions on organizational change as $t$-value has been found statistically insignificant. Moreover, significant difference has been found between the group of male and female teachers on the degree of perceived job satisfaction towards organizational as ' $t$ ' -2.47 has been found statistically significant at .02 level of confidence, although, both the groups scored higher above average score on job satisfaction. It is interesting to note that male group of teachers were found more satisfied while working in +2 private schools during COVID - 19 than female teachers comparatively. Finally, obtained results were discussed in detail by highlighting the probable reasons in the light of research diary as prepared during the investigation.

Keywords: Job Satisfaction, Organizational Change, male, female, teachers, North Bihar, India.

Copyright $(02020$ The Author(s): This is an open-access article distributed under the terms of the Creative Commons Attribution 4.0 International License (CC BY-NC 4.0) which permits unrestricted use, distribution, and reproduction in any medium for non-commercial use provided the original author and source are credited.

\section{INTRODUCTION}

The present study is aimed at studying the job satisfaction towards organizational change among male and female teachers working in +2 private schools of North Bihar, India. as it is often observed that in the present day modern world working life has become probably the most significant aspect of one's life because people keep themselves engaged in some job where they spend much more time than in any activity except sleeping. Those who are working in any industry or organization may develop apprehensions and indistinguishable as a result of various unpleasant stressful and threatening work situations due to organizational change. It is because of the fact that most of the organizations have brought changes in their organizations especially in the present times of COVID - 19. Therefore, the phenomenon of organizational change in general and job satisfaction in particular, is more important to be studied, especially in the work situation to understand the employees' job satisfaction towards change. It is because of the fact that resistance to change may be the cause of low job satisfaction which plays an important role as one of the important of job satisfaction.

These days research interest in job satisfaction, occupational stress coping and health has grown considerably towards organizational change during the present time of COVID - 19 outbreaks. It is because of the fact that job related stressors are unavoidable in working life. In many job situations, particularly in 
human services, one of the major sources of stress is whether the person is satisfied with the job or not. Thus, the present study is of utmost value to study the job satisfaction in relation to organizational change in the present times of COVID - 19 outbreaks.

Change is the law of nature and it cannot be avoided at any cost. One of the few elements of the work environment that is recognized as being constant is "change". At present, nearly all organizations are undergoing the process of change. Some are in a constant state of change while others feel to bring change periodically. The transitory phase of change usually receives a great resistance because organizational workers usually fear of losing their importance, promotion, or authority in view of change in the organization, though, it is not generally true however, organizational change in this modern era has become necessary in the wake of changing technology for ensuring the existence and competitive survival of an organization.

Most definitions of organizational change draw attention to its convergent nature, it may bring restructuring of the organization, change in technology, diversification of organization or its products, etc. if organizations do not incorporate the impact of organizational output in their structure, then very soon they may have to undergo another structural change. Organizational structural change might come into focus in establishing responsibilities, allocating tasks, defining communication and improving control systems. On the basis of past researches Ahmad [1] pointed out that organizational change, today, encompasses all round change in technological, financial, material and in the potential human resources which have been witnessed from the contention of Leavitt [2] who emphasized that organization can be changed by altering its structure, its technology and/or its people.

It is also pertinent to point out that change and human attitudes are closely related because attitude are important when any change is brought into the organization, then how change will affect one's need and satisfaction in the organization [3]. The reaction to change may be exhibited in the following forms:

- Acceptance: If an individual perceives that the change will affect him favorably, he accepts it.

- Resistance: If the individual employee feels that the change will affect him unfavorably, he resists it. Resistance to change becomes more forceful when the person concerned has a feeling that through resistance he may eliminate the change.

- Indifference: Sometimes people fail to realize the impact of change or they feel that they will not be affected by the change, either way they remain indifferent.
- Force acceptance: Sometimes people are forced to accept the change, though they may resist it at initial stages but when change forces overpower resistance forces people have to accept it.

Apart from the above mentioned text, it is also important to point out that feelings are the part of each man's personal make-up and cannot be judged by human attitudes and their reaction to change. Generally people have a tendency to resist changes, so, planned change is brought by every organization because in planned change every one gets ample opportunity to go by with the demands of change to serve the organization $[4,5]$.

Human beings are certainly familiar with change and often prove them quite adaptive to it. As we know that the faster pace of change required by the electronic age, of the shift to a service economy, and of the growth of global competition has made the solution of the requirement even more important. When manager use their most logical arguments and persuasive skills to support a change, they frequently discover that employees remain unconvinced of the need for it.

Change is any alteration occurring in the work environment that affects the ways in which employees must act. These changes must be planned or unplanned, catastrophic or evolutionary, positive or negative, strong or weak, slow or rapid, and stimulated either internally or externally [6].Regardless of their source, nature, origin, pace, or strength, changes can have profound effects on their recipients [7].

It is an important to point out that many of the organizational changes that occur on a daily basis are somewhat slight. They may affect only a few people, and they may be incremental in nature and relatively predictable. For example as new procedures evolve or as new members are added to a work group specially during COVID - 19 pandemic, existing employees generally do not need to change all dimensions of their jobs or acquire totally new behaviors. In such situations a new equilibrium may reach readily.

A wide variety of force, however, may bring about more impressive change that touches the entire core of an organization. Many of these have become much more common as the economy, competition, and pace of technological change may become more volatile.

Some changes originate within the organization, but many come from the external environment. Government passes laws, and the organization must comply. New development in technology arises, and products must incorporate the changes. Competitors introduce new services, and the firm must respond. Then there are pressures from 
customers, labor unions, communities and other who initiate changes. Although, stable environment means less change, dynamic environment, are now the norm and they require more change. On occasion they can cause difficulties for employees especially in this incident.

Before terminating the complete descriptions of organizational change it is necessary to point out some of the observations experienced by the present investigators. Change is everywhere, and its pace is increasing due to COVID - 19. The work environment is filled with change that often upsets the social system and requires employees to adjust especially in the times of COVID - 19 outbreaks. Change has costs as well as benefits, and both must be considered to determine net effects. Moreover, employees tend to resist change because of its costs, including its psychic costs. Resistance to change can stem from the change process itself, the way it was introduced, or the perception of inequitable impact. It is further seen that it can be logical, psychological, or sociological. Hence, the present piece of research work is to study the perceived reactions on job satisfaction towards organizational change.

Job satisfaction has been defined as the degree to which employees have a positive affective orientation towards employment by the organization [8]. Another defines job satisfaction as an affective (emotional) reaction to a job that results from the incumbents' comparison of actual outcomes with those that are desired [9]. Job satisfaction is the favorableness or unfavorable ness with which employees view their work. It results when there is a misfit between job requirements and the wants and the expectations of employees. Many researchers found that job related stress factors are related to variables like role ambiguity, role conflict, employee performance and satisfaction, work overload, need for achievement and organizational effectiveness [10-12].

Job Satisfaction, as the name suggests, is the feeling of contentment or a sense of accomplishment, which an employee derives from his/her job. It is a result of appraisal that causes one to attain their job values or meet out their basic needs. It helps in determining, to what extent a person likes or dislikes his/her job.

The employee's attitude towards the job and organization as well becomes positive when they realize that their job facilitates them in achieving their needs and values, directly (by performing it) or indirectly (by the package they get). In short, it represents the difference between employee's expectations and experience he/she derives from the job. The wider the gap, the more is the dissatisfaction.
In addition to the above context it is important to point out that, there is a general assumption that the teachers do not have satisfaction in their jobs. It seems to be a growing discontentment towards their job as a result of which standards of education are falling. It is generally observed that teachers are dissatisfied in spite of different plans and programs which have been implemented to improve their job, although, job satisfaction consists of the total body of feelings about the nature of the job promotion, nature of supervision etc. that an individual has about his job. If the sum total of influence of these factors gives rise to feelings of satisfaction, the individual has job satisfaction towards their job assigned.

Apart from the above context it is important to point out that job satisfaction is related to working conditions and level of professionalism is a key factor in successfully recruiting and retaining teachers [30].

It is often observed that the studies conducted in different countries have shown that teacher autonomy is important for job satisfaction. Similarly, it can be viewed that teacher professionalism is not just about salaries, it is also about intrinsic benefits of teaching. Moreover, educators believe that recognizing teaching as a profession and developing professional teachers is a possible solution to teachers' lack of motivation and satisfaction, professionalism and empowerments as well as teacher stress [14]. According to National Center for Education Statistics [15] near about $20 \%$ of government school teachers and $28 \%$ of private school teachers left because they wanted to pursue other career opportunities, they were dissatisfied with the profession, or because they desired better salaries or benefits, of the teachers who reported being dissatisfied with teaching as a career, the majority specified concerns with inadequate support from the administration and poor student motivation to learn. In addition to it, Kaur [16] reported that teachers working under private management were found more satisfied than those in government school.

Most of the Western studies demonstrated the effects of stressors or burnout in relation to job anxiety and satisfaction $[17,18]$. Studies on different occupational groups have shown that different organizational stressors are positively related to general or job anxiety. It is important to be pointed out that in India empirical studies have dealt with organizational role stress and job satisfaction [19]. Available researches also suggest that investigators concentrated their studies either on role conflict or role ambiguity as stressors with other organizational variables [16, 20]. These studies have not been probed into with relation to working women and their job related stress factors.

It is often observed that working women teacher suffer from more stress than men teacher in many respects. Various studies indicate that women at 
work frequently suffer more stress than the male because they have to combine their jobs with running a home, caring for their husbands and coping with children's ailments $[21,22]$.

\section{Aims and Objectives of the present study}

Having reviewed the available literature on the phenomena various studies have been found as mentioned above but has not been covered the area chosen by the present investigators specially on the aspect of job satisfaction towards organizational change during the period of COVID - 19 pandemic. Moreover, it is important to mention that very meager number of studies is available in Indian context but none of the studies have been found with reference to +2 private school teachers with particular reference to North Bihar. It is still unexplored area and needs special attention to be studied during the period of COVID - 19 pandemic. Thus the present study is of immense value and it will fill the void of knowledge in the area desired by present investigators. It is also important to mention that the role of women teacher is radically changing because a large number of women have begun to work full time and, they are aspiring to the same organizational ladders as their male counterparts. Consequently, it is often observed that working women teacher in +2 private schools are exposed to dual role of home maker and career person, encounter with daily stress.

\section{HYPOTHESES}

On the basis of the broad aims and objectives of the present study the following hypotheses were formulated.

1. There will be no significant difference between the group of male and female teachers working in +2 private schools in terms of their perceived reactions on organizational change during COVID - 19 outbreaks.

2. Male teacher will have more degree of perceived reactions on organizational change than female teachers in +2 private schools during COVID - 19 outbreaks.

3. There will be no significant difference between the group of male and female teachers working in +2 private schools in terms of their degree of job satisfaction during COVID - 19 pandemic

4. Male teacher will have greater degree of job satisfaction towards organizational change than female teachers during COVID - 19 outbreaks

\section{RESEARCH METHODOLOGY Sample}

For the present piece of research work, total sample consisted of one hundred fifty $(\mathrm{N}=150)$ comprising Male $(n=75)$ and female $(n=75)$ which were randomly selected from different +2 private schools located in and around North Bihar, India. The districts, viz., Darbhanga, Madhubani and Samastipur were given priority for collecting the data. All respondents' age were ranged between $25-55$ years.

\section{Tools Used}

To achieve the objective of the present enquiry the following tools were used:

(a) Job Satisfaction Scale: For measuring the job satisfaction of the +2 private school teachers, a scale developed by Singh and Sharma [23] was used. The scale consisted of 30 items having five alternatives on Likert's 5-point scale from strongly agree to strongly disagree. In this scale higher score indicates higher degree of job satisfaction.

(b) Organizational Change Scale: For the measurement of Textiles Industries employees' perceived reactions towards organizational change, a scale developed by Rahman and Akhtar [24] was used. The scale consisted of 25 items and all the items are positively phrased except the one, i.e., item No.6. The subjects were required to give responses to the items on a 5- point scale ranging from "Strongly Agree" to "Strongly Disagree". The reported split-half reliability of the scale is $\mathrm{r}=.85$ which confirms the reliability of organizational change scale.

(c) Biographical Information Blank: For tapping information pertaining to biographical variables self-made biographical information blank was prepared for interpreting the results. It includes age, sex, income, teaching experience, number of dependents, type of family and area of locality, etc.

\section{Procedure}

The above questionnaire schedules along with biographical information blanks were administered on one hundred fifty teachers (male and female) individually who are working in +2 private schools located in and around the districts of North Bihar covering Darbhanga, Madhubani and Samastipur. The scoring was done on the basis of norms prepared by the authors for the items of the scales. The obtained individual scores for job satisfaction and organizational change were summed up separately and the obtained data were analyzed with descriptive statistical techniques.

\section{RESULTS AND DISCUSSION}

In pursuit of obtaining the results table -1 revealed the clear cut picture regarding the differences between male and female teachers working in +2 private school in terms of their perceived reactions towards organizational change. From the table -1 , it can be observed that no significant difference between the group of male and female +2 private school teachers has been found statistically, although male teachers in +2 private schools have been found more prone towards organizational change during COVID - 19 than female 
group of teachers especially where from the present study has been carried out. The obtained results seem to be logical that the male group of teachers working in +2 private schools scored high mean score on perceived organizational change i.e. 91.06 with a standard deviation (SD) of 18.78 and at the same time private school female teachers obtained a organizational change mean scores i.e. 86.51 with SD of 17.56 comparatively. Both the group of male and female teachers working in +2 private schools positively inclined to their perceived reactions with slightly difference. Thus, insignificant difference between the two group of male and female on perceived reactions on organizational change has been found. Hence the proposed hypothesis i.e. "there will be no significant difference between the group of male and female teachers working in +2 private schools in terms of their degree of perceived reactions on organizational change stands accepted. From the table, it could be understood that the mean value of male group of +2 school teachers is higher than their female counterparts during COVID - 19 outbreaks.

Table-1: Showing Mean, SD, and' $t$ ' Between the Group of Male and Female Teachers working in +2 Private Schools on the Degree of Perceived Reactions towards Organizational Change

\begin{tabular}{|c|c|c|c|c|c|}
\hline Groups & $\mathbf{N}=150$ & Mean & SD & t - value & Level of significance \\
\hline Male Pvt. School Teachers & $\mathrm{n}=75$ & 91.06 & 18.78 & 1.52 & Insignificant \\
\hline Female Pvt. School Teachers & $\mathrm{n}=75$ & 86.51 & 17.56 & & \\
\hline
\end{tabular}

Table-2: Showing Comparative Levels of Perceived Organizational Change between the Group of Male and Female Teachers Working in +2 Private Schools of North Bihar, India

\begin{tabular}{|c|c|c|c|c|}
\multirow{3}{*}{ Levels } & \multicolumn{4}{|c|}{ G R O U P } \\
\cline { 2 - 5 } & Male Pvt. School Teachers & Female Pvt. School Teachers \\
\cline { 2 - 5 } & $\mathrm{n}=75$ & Percentage \% & $\mathrm{n}=75$ & Percentage \% \\
\hline High & 43 & $57.33 \%$ & 38 & $50.67 \%$ \\
\hline Moderate & 28 & $37.33 \%$ & 18 & $24 \%$ \\
\hline Low & 04 & $5.33 \%$ & 19 & $25.33 \%$ \\
\hline
\end{tabular}

Table -2 is the extension of table -1 which reveals the clear cut picture pertaining to the comparative levels of perceived reactions of organizational change. From the table -2 it can be observed that 57.33 percent of male private school teachers have shown higher degree of acceptability to organizational change in comparison to female teachers i.e., 5.67 percent which low as compared to male +2 private school teachers, whereas, 37.33 percent of male teachers working in +2 private schools have shown moderate level of perceived reactions on organizational change as compared to their female counterparts i.e., 24 percent. Moreover, 25.33 percent of female +2 private school teachers reported low but favorable reactions to organizational change in comparison to male teachers. The present obtained results seem to be logical in the sense, whatever the changes has been adopted by the administration of private schools on the guidelines of Govt. of India and World Health Organization (WHO), they are all agreed to accept the changes accordingly during the period of COVID - 19 pandemic. Hence, both the group inclined to accept the changes, male group teachers had shown little higher degree to change. The obtained and presented results can be observed by the following figure:

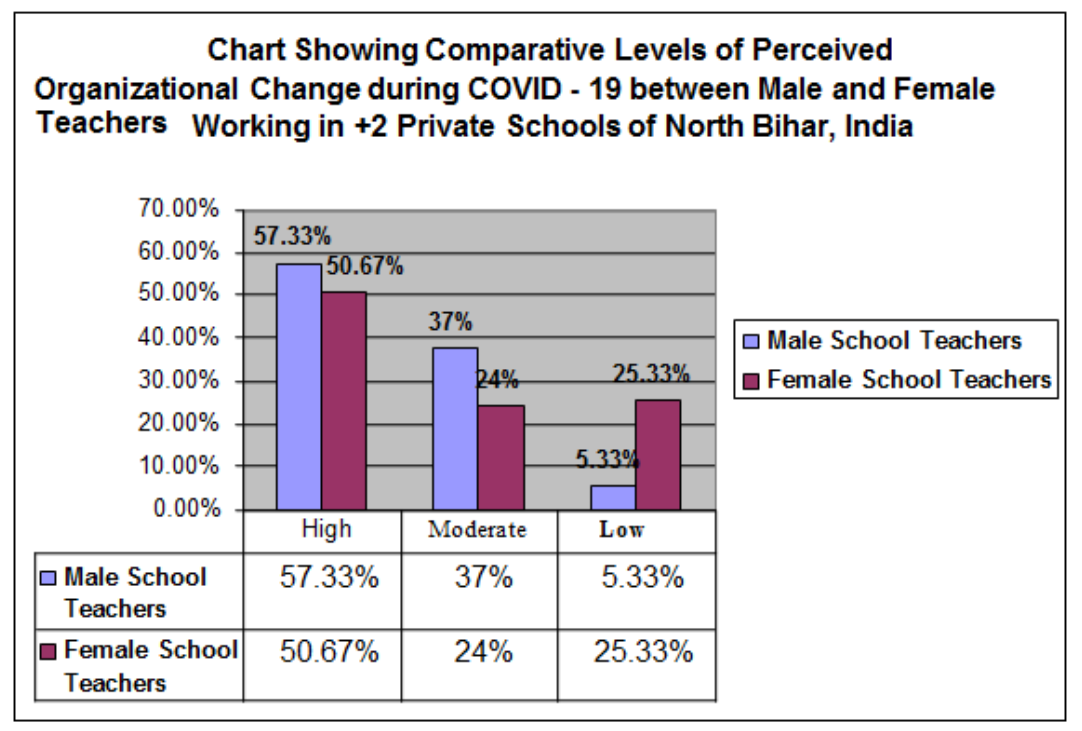


Table-3: Showing Mean, SD, and' $t$ ' Between the Group of Male and Female Teachers working in +2 Private Schools on the Degree of Job Satisfaction towards Organizational Change

\begin{tabular}{|c|c|c|c|c|c|}
\hline Groups & N=150 & Mean & SD & t - value & Level of significance \\
\hline Male Pvt. School Teachers & $\mathrm{n}=75$ & 103.73 & 21.24 & 2.47 & 0.02 \\
\cline { 1 - 4 } Female Pvt. School Teachers & $\mathrm{n}=75$ & 95.21 & 20.70 & & \\
\hline
\end{tabular}

Table-3 of the obtained results reveals the clear cut picture regarding the significant difference between the male and female teachers working in +2 private schools. Male +2 private school teachers are more satisfied with their jobs and they feel much better by adopting changes during COVID - 19 than female group of private school teachers especially from where the present piece of research work has been completed. From the table-3 it can also be observed that male teachers of private schools scored better on job satisfaction scale as their job satisfaction Mean Score is 103.73 with an SD 21.24 has been found high in comparison to the job satisfaction of Mean Score of female teachers i.e. 95.21 with an SD 20.70. Hence, significant difference has been found between the groups as the $t-2.47$ have been found significant at 0.02 level of confidence. Thus, the proposed hypothesis i.e. there will be no significant difference between the group of male and female teachers working in +2 private school stands rejected. The results seem to be logical that during COVID-19 outbreaks all the employees had taken the precautions as per guidelines of the government but they are afraid from this pandemic and every time they are discussing on this evil - when it will finish, nobody knows except God but instead of this pandemic all employees are interested to work from home for the nation's building development, process and communication. Moreover, on the other hand, female group of teachers seem to be more anxious about their job career, hence they scored low but favorable reactions on job satisfaction towards organizational change. Therefore, male group of +2 school teachers reported higher degree of job satisfaction towards organizational change than female group of teachers especially working in +2 private schools of North Bihar.

Table-4: Showing Comparative Levels of Perceived Degree of Job Satisfaction towards Organizational Change between the Groups of Male and Female Teachers Working in +2 Private Schools of North Bihar, India

\begin{tabular}{|c|c|c|c|c|}
\hline \multirow{3}{*}{ Levels } & \multicolumn{4}{|c|}{ G R O U P } \\
\cline { 2 - 5 } & Male Pvt. School Teachers & Female Pvt. School Teachers \\
\cline { 2 - 5 } High & $\mathrm{n}=75$ & Percentage \% & $\mathrm{n}=75$ & Percentage \% \\
\hline Moderate & 52 & $69.33 \%$ & 42 & $56 \%$ \\
\hline Low & 3 & $26.67 \%$ & 25 & $33.33 \%$ \\
\hline
\end{tabular}

Table -4 is the extension of table -3 depict the picture regarding the comparative levels of perceived reactions on job satisfaction between male and female +2 private school teachers working in North Bihar. From the table - 2, it can be observed that 69.33 percent of male teachers have shown higher degree of job satisfaction in comparison to female teacher i.e. 56 percent which is low comparatively. 33.33 percent of female +2 school teachers reported moderate levels of perceived job satisfaction in comparison to male teachers i.e. 26.67 percent comparatively which is low than female +2 school teachers. So far as the low levels of perceived job satisfaction is concerned, only 4 percent of male school teachers are found to have low level but favorable reactions on job satisfaction towards organizational change in comparison female group of teachers i.e. 10.67 percent which is higher than male group of teachers working in +2 private schools. Thus, the hypothesis i.e. "male teachers will have more degree of perceived job satisfaction than female teachers in +2 private schools of North Bihar, India" also stands accepted. The obtained results seem to be logical especially in the context of North Bihar in the sense that males are enjoying much more with the school teaching jobs than female group of teachers during the COVID 19 pandemic, although still female have their dual roles, it is because of the fact that in addition to the household works all women in this area from where the present study has been carried out, they are very much keen to contribute something in catering the needs and demands of the family by doing private teaching job. Hence, significance of difference has been found. Above discussed results can also be observed by the following chart. 


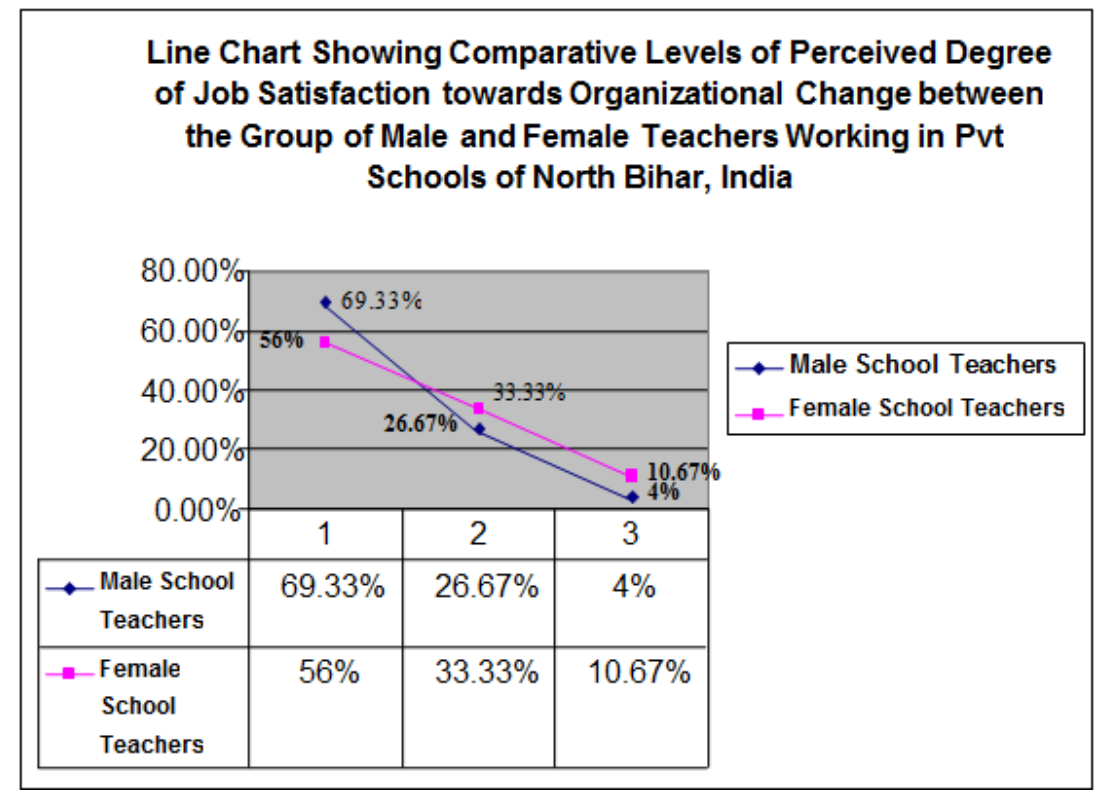

The above obtained results seem to be logical and can be interpreted that all +2 private school teachers have shown better score on job satisfaction towards perceived organizational change from where the present piece of research work has been completed. It is important to point out that all +2 private schools in North Bihar have unique work culture in their schools but instead of this there is a need of provision of better physical facilities in private schools for both the group of male and female and also some incentives such as job security, financial benefits, etc should be given as on the guidelines of Government policies during the COVID -19 outbreaks.

\section{CONCLUSIONS}

In the light of the obtained results and its interpretations the following conclusions have been drawn:

1. Significance of difference has not been found between the group of male and female teachers working in +2 private schools on their degree of perceived reactions towards organizational change in North Bihar where from present piece of research work has been carried out.

2. Male +2 private school teachers have shown higher degree of perceived reactions to organizational change in comparison to their female counterparts but insignificant difference is found.

3. Significance of Difference has been found between the group of male and female teachers working in +2 private schools in North Bihar in terms of their degree of job satisfaction.

4. Male teachers have been found to have greater degree of job satisfaction than female teachers in +2 private schools of North Bihar.

5. Observations have revealed the fact that there should be a provision of better physical facilities such as job security, financial benefits like other government institutions etc for maintaining the congenial environment in +2 private schools especially during COVID - 19.

\section{REFERENCES}

1. Ahmad, Anis. Occupational Stress and Certain Biographical Variables as Predicators of Organizational Change. Journal of community Guidance and Research-An International multidisciplinary Cross -Cultural Journal. 1994; 2(2), 95103.

2. Leavitt, Harold J. "Applied Organizational change in Industry: Structural, Technical \& Human Approaches", in W.W. Cooper, H.J. Leavitt and M.W. Shelly II, eds., New Perspective in organization Research. New York: Wiley. 1964; 55-71.

3. Ahmad Anis. Enhancing Business Effectiveness through Organizational Change. Business Psychology. Edited by Novrattan Sharma and Amrita Yadav. Global Vision Publishing House, New Delhi. 2010.

4. Ahmad, Anis. Organizational Commitment Vs Organizational Change: A comparative study of Blue Collar and White Collar Employees of Saree Manufacturing Companies. Social Science International. 2000; 16(1): 20-23.

5. Ahmad, Anis. Perceived Organizational Change with reference to occupational stress JIAAP. 2001; 27(1): 83-88.

6. Tom Duening. Our turbulent Times: The case for Evolutionary Organizational Change. Business Horizons, January-February. 1997; 2-8.

7. McKinley A and Starkey K. Competitive Strategies and Organizational. Organization Studies. 1988; 9(4): 555 - 557.

8. Price JL. The study of turnover. Ames, IA: Lowa State University Press.1997.

9. Cranny CJ, Smith PC and Stone EF. Job Satisfaction: How people feel about their jobs and 
how it affects their performance, Lexington Books (New York). 19992; $103-368-63$.

10. Dunnette MD. Handbook of Industrial psychology. Bombay: Himalaya Publishing House; 1976.

11. Ghosh PK and Ghorpade MB. Industrial psychology: Himalya Publishing House; 1981.

12. Mohanty G. Role ambiguity, role conflict and certain job attitudes. Sedme. 1986; 3, 24-40.

13. Stansbury $\mathrm{K}$ and Zimmerman J. Lifelines to the Classroom: Designing Support for Beginning Teachers. Knowledge Brief, Son Fransisco, CA: West Ed.2000.

14. Pearson LC and Moomaw W. Continuing Validation of the teaching autonomy scale. The Journal of Education Scale. 2006; 100 (1), 44-51.

15. National Centre for Education Statistics. Teacher Professionalization and Teacher Commitment: A Multilevel Analysis, US Department of Education, NCES. 1997; 97-069.

16. Weick K and Quinn R. Organizational change and development. Annual Review of Psychology. 1999; 50, 361-386.

17. Cohen S. After effects of stress on human performances and social behavior. Psychological Bulletin. 1984; 88: 82-108.
18. Powell M. Occupational problems of professional men: Dentists and Pharmacists. Occupational Psychology. 1972; 46, 53-67.

19. Pestonjee DM and Singh UB. Job Satisfaction as a function of role stress, locus of control participation and organizational climate in an electric supply company. I. I. M. Ahmedabad. 1982.

20. Tharakan PNO. Occupational Stress research: A critical review, XXV Annual Conference of the Indian Academy of Applied Psychology, Osmania University, Feb. 1988; 25-27.

21. Singh, Baljit and Amarbit. A study of job satisfaction as related to marital adjustment of working women. Manas. 1986; 33, 55-58.

22. Steffi Briau D and Ashbaugh, Donald. Dual career planning, marital satisfaction and job stress among women in dual career marriages, Journal of Business Psychology. 1986; 1, 114 -123.

23. Singh and Sharma. Job Satisfaction Scale, National Psychological Corporation, Agra. 1999.

24. Rahman I and Akhtar SS. 'Organizational Change Scale', Department of Psychology, Aligarh Muslim University, Aligarh, India; 1991. 